\title{
An integrated assessment of seawater intrusion in a small tropical island using geophysical, geochemical, and geostatistical techniques
}

\begin{abstract}
In this study, geophysics, geochemistry, and geostatistical techniques were integrated to assess seawater intrusion in Kapas Island due to its geological complexity and multiple contamination sources. Five resistivity profiles were measured using an electric resistivity technique. The results reveal very low resistivity $<1 \Omega \mathrm{m}$, suggesting either marine clay deposit or seawater intrusion or both along the majority of the resistivity images. As a result, geochemistry was further employed to verify the resistivity evidence. The Chadha and Stiff diagrams classify the island groundwater into $\mathrm{Ca}-\mathrm{HCO} 3, \mathrm{Ca}-\mathrm{Na}-\mathrm{HCO} 3, \mathrm{Na}-\mathrm{HCO} 3$, and Na$\mathrm{Cl}$ water types, with $\mathrm{Ca}-\mathrm{HCO} 3$ as the dominant. The $\mathrm{Mg} 2+/ \mathrm{Mg} 2++\mathrm{Ca} 2+, \mathrm{HCO} 3-/$ anion, $\mathrm{Cl}-/ \mathrm{HCO} 3-, \mathrm{Na}+/ \mathrm{Cl}-$, and $\mathrm{SO} 42-/ \mathrm{Cl}-$ ratios show that some sampling sites are affected by seawater intrusion; these sampling sites fall within the same areas that show low-resistivity values. The resulting ratios and resistivity values were then used in the geographical information system (GIS) environment to create the geostatistical map of individual indicators. These maps were then overlaid to create the final map showing seawater-affected areas. The final map successfully delineates the area that is actually undergoing seawater intrusion. The proposed technique is not area specific, and hence, it can work in any place with similar completed characteristics or under the influence of multiple contaminants so as to distinguish the area that is truly affected by any targeted pollutants from the rest. This information would provide managers and policy makers with the knowledge of the current situation and will serve as a guide and standard in water research for sustainable management plan.
\end{abstract}

Keyword: Geophysics; Geochemistry; Geostatistics; Groundwater; Seawater intrusion; Ionic ratio; Small island 